\title{
The Cooperative Game Research of Emergency Material Reserve in Beijing City
}

\author{
Xiangguo Ma, Huihui Su, Liming Sui \\ Beijing Wuzi University, Beijing, China \\ Email:136612043@qq.com, 1226219696@qq.com,851072956@qq.com
}

Received 10 May 2016; accepted 18 July 2016; published 25 July 2016

\begin{abstract}
The combination of government reserve and enterprise reserve is one of the main models of emergency material storage in Beijing City. In recent years, China was advocating the government and enterprises to establish multi level and multi mode of the storage mode to save cost and improve efficiency. This paper uses mathematical model to establish a cooperative game premise condition, then analyses the emergency material storage cooperative game between the government and the enterprise and establishes binding cost apportionment and punishment measures to get a stable cooperation, so that both sides obtain the biggest benefit. Finally, based on the game of government and enterprise cooperation establish cost lowest Beijing emergency materials storage and transportation mode.
\end{abstract}

\section{Keywords}

Emergency Supplies, Storage, Cooperation, Game

\section{Introduction}

Social emergencies always do occur frequently, whether in public safety or in natural disaster and they usually cause social disorder and great economic losses. According to statistics, emergencies such as natural disasters, accident disasters and public safety events caused millions of casualties and economic losses up to $¥ 650$ billion, about $6 \%$ of our national GDP, every year in our country [1]. To minimize casualties and economic losses, we must not only prevent and forecast them but must work also well when they occurred. Storing emergency supplies, as an important part of emergency work, directly relate to the efficiency of emergency work. For the past few years, scholars in our country have come up with establishing multi layer and multi pattern's storing way via cooperation between government and enterprise to save costs and improve efficiency. In the storing supplies aspect, the government can store supplies by themselves or ask the enterprise which product them to help store, and the enterprise can accept it or not according to their state. Therefore, how to storing emergency supplies is a game between government and corporation.

\section{Game Theory}

Game theory study that how to maximize the utility of decision-maker with given information and how to bal- 
ance decisions between different decision makers. In economics, equilibrium means making correlative variables at their stable values. Nash equilibrium is defined as a combination of strategic decisions consisting of all participants' optimal decision, and even if, with others given decisions, no one has enough reason to break the balance.

Basic elements in a game are participants, which are a decision-makers and whose objective is to maximize its utility through making its optimal action (or strategy). It may be a person or a group such as enterprise, country and so on. Action or strategy is the participant's decision variable. Pay function, is the certain utility level a participant obtained in specific strategies.

Cooperative game is defined as a game which has a binding cooperative agreement. Therefore, the essential difference between cooperative game and non-cooperative game depend on if there has a binding agreement [2].

\section{The Conditions of Cooperation Game}

Besides satisfying emergency needs, another essential factor is cost when government makes the decision how to store emergency goods. When making the decision, government must consider the different between economic profit and storing cost during cooperation. For this reason there has a specific condition during the cooperative game on storing supplies between government and enterprise, that is building a cost model to determine whether the supplies should be stored using cooperative storing pattern on the basis of the goods' feature (main factors are storing cost and shelf-life in this case).

\subsection{Parameters Setting}

Assuming that $\mathrm{u}$ is the cost of a certain goods, $\mathrm{p}_{0}$ is its market price, $t$ is shelf-life, $\mathrm{u}_{0}$ is expired residual price, $\rho$ is the probability that a emergency event which need this goods happens during shelf-life $t$ (emergency event below indicate this kind of event), $C_{1}$ is the cost that government pays when storing a piece of good in a unit time, $\mathrm{C}_{2}$ is the cost that enterprise pays when storing a piece of good in a unit time, $\mathrm{C}_{1}$ is the unit paying cost of government in a unit time, $C_{2}$ is the unit paying cost of government in a unit time. The paying cost is defined as cumulative value of all pay cost which subtracts profit, also called final paying cost.

Because there has not only the storing cost, may also has other cost and profit during storing process. For instance, the expired cost of government and the profit that enterprise obtained from selling the goods. So here we distinguish storing cost and paying cost.

$$
\begin{aligned}
\mathrm{C}_{1} & =\rho \cdot \text { OccuredUCT }+(1-\rho) \cdot \text { Not OccurredUCT } \\
& =\rho \cdot C_{1}+(1-\rho) \cdot\left[c_{1}+\left(\mathrm{p}_{0}-\mathrm{u}_{0}\right) / t\right]
\end{aligned}
$$

\subsection{Paying Cost of Enterprise during Storing}

Supposing that that kind of goods is stored by enterprise, owing to it has liquidity, we can sell them timely before expiry, so here we do not consider the expiration. Same as description before, during shelf-life of the good, emergency event also has two status, occurred or not occurred. If occurred, enterprise can obtain the selling profit besides storing cost. Assuming $t_{0}\left(0 \leq t_{0} \leq t\right)$ is the occurred time, if not occurred, there has only storing cost, similarly we can get a expected value of a unit's paying cost per unit time, Then, the unit paying cost that government pays when storing that goods per unit time is: (UCT means a unit's paying cost per unit time)

$$
\begin{aligned}
\mathrm{C}_{2} & =\rho . \text { OccuredUCT }+(1-\rho) \cdot \text {.Not OccurredUCT } \\
& =\rho\left[c_{2}-\left(\mathrm{p}_{0}-u\right) / t_{0}\right]+(1-\rho) c_{2} \leq \rho\left[c_{2}-\left(\mathrm{p}_{0}-u\right) / t\right]+(1-\rho) c_{2}
\end{aligned}
$$

Owing to $t$ is the last time that event occurred, in this case the cost of enterprise will be the most expensive, when calculating the cost, we should use the most expensive cost. As a result:

\subsection{The Analysis of Cost Model}

There are three cases as follow:

(1) If $\mathrm{C}_{2}<0$, that indicates enterprise will still obtain profit except storing cost when helping government to store that kind of goods, in this case, enterprise will cooperate with government, because they do not, they will hardly have purchasing contracts with government, that cause $C_{2}=0$, and not benefit government. With enter- 
prise's cooperation, it will help government to reduce their storing cost.

(2) If $\mathrm{C}_{2} \geq 0 \& \mathrm{C}_{1} \geq C_{2}$, that means storing cost of enterprise is beyond its profit, and that is not willing of enterprise. Owing to costly storing cost more than enterprise, government need enterprise's cooperation to reduce storing cost and pay compensation to enterprise, that, Extra Payment $\theta$ (for storing a piece of good in a unit time). how much Payment is appropriate, enterprise 's goal is gaining more profit, thus extra payment must be more than its storing cost, that is $\theta \geq \mathrm{C}_{2}$, Same as enterprise, for government extra payment must be less than its storing cost. In conclusion, only if extra payment is between enterprise's storing cost and government's storing cost, that is $\mathrm{C}_{2} \leq \theta \leq \mathrm{C}_{1}$, enterprise and government both get the most profit through cooperation. And otherwise, $\theta$ out of that range, there will not have any cooperation between them.

(3) If $C_{2} \geq C_{1}$, and if cooperation established, enterprise desired extra payment $\theta \geq C_{2}$, but $\theta \geq C_{1}$, extra payment government pays is beyond its storing cost, and government will not accept it.

To sum up, provided government's storing cost is more than enterprise's, that is $C_{2} \geq C_{1}$, Cooperation between them may exist. That not only is the precondition of cooperation game, but also provides a foundation of how to store a certain goods for government.

\section{The Analysis of Cooperation Game}

Cooperative game depend on if enterprise and government both have profit, that is $C_{1} \geq C_{2}$. An important part of cooperative game is if the cooperative contract is binding, without a binding contract, if either of them betrays the contract at any time, that will cause another's loss, thereby the contract will become instable. Another part depends on how to distribute profit and how to share cost. Distributing program must be accepted by every participant in cooperation. Even if one does not agree, the contract's stability will be influenced. Now then, let's analyze cooperation with no cost sharing and no punishment is stability or not

\subsection{No Punishment and No Cost Sharing Gaming Model}

(1) Building gaming model

Participant: government and enterprise; Strategy set: (cooperation, betrayal), Table 1 show the paying function of every participant. 0 .

In (betray, betray), emergency goods are stored by government, the cost is storing cost $C_{1}$, enterprise cost is

In (betray, cooperate), government and enterprise both store goods, government cost is $C_{1}$, Enterprise cost is $C_{2}$, In (cooperate, betray), goods do not be stored, government cost is $C$, enterprise cost is 0 .

In (cooperate, cooperate), goods are stored by enterprise, enterprise cost is $C_{2}$, government's is 0 .

The pay cost has the following relations.

(1) $0<\mathrm{C}_{1}<<C$

On the condition of the government self storage, $\mathrm{C}_{1}>0$ is obviously. If the enterprise takes betrayal strategy and the government did not carry out emergency material storage, when emergency events happen, emergency material without the timely supply, the loss is immeasurable, therefore.

(2) $\mathrm{c}_{2} \geq \mathrm{C}_{2} \& C_{2}>0$

Enterprise paying cost $\mathrm{C}_{2}$ is storing cost $\mathrm{C}_{2}$ exclude selling profit, $C_{2} \geq C_{2}$ because selling profit is positive. $\mathrm{C}_{2} \geq 0$ or $\mathrm{C}_{2}<0$ as describe before, the strategies in this case will discuss in section "stable cooperative gaming model”.

(2) Analysis of game model

(1) If government betrays, enterprise cannot obtain profit from selling goods. If enterprise still cooperates, it will pay the storing cost $C_{2}$, that is $C_{2}>0$, then betrayal is optimal and unique strategy for enterprise.

Table 1. Paying function.

\begin{tabular}{cccc}
\hline & & \multicolumn{2}{c}{ Enterprise } \\
\cline { 3 - 4 } & & Betray & Cooperate \\
\hline \multirow{2}{*}{ Government } & Betray & $\left(\mathrm{C}_{1}, 0\right)$ & $\left(\mathrm{C}_{1}, \mathrm{C}_{2}\right)$ \\
& Cooperate & $(C, 0)$ & $\left(0, \mathrm{C}_{2}\right)$ \\
\hline
\end{tabular}


Similarly, when enterprise betrays, government cost $C$ will be more than betrayal cost $C_{1}$ if cooperating, that means government must choose betrayal as its optimal strategy. Consequently, (betray, betray) is a Nash equilibrium strategy.

(2) In another case, with government's cooperation, $C_{2} \geq 0$, enterprise's cost is $C_{2}$ during cooperation, betrayal cost is 0 , betrayal is optimal strategy for enterprise(discussed in (1)). Same as before (betray, betray) is a Nash equilibrium.

At this point, there are two Nash equilibrium (betray, betray) and (cooperate, cooperate). If $\mathrm{C}_{2} \geq 0$, that is (cooperate, cooperate), Equilibrium does not exist, then (cooperate, cooperate) is not unique equilibrium, the cooperation between them is instability, they will betray each other simultaneously. On the another hand, whether cooperating or not involves their risk aversion, in the field of emergency, government don't want there to be any risk, enterprise also know that clearly, Therefore, before Establishing a binding cooperative agreement, the only equilibrium between them is (betray, betray).

It can be seen that, without rational cost sharing, they will not cooperate with each other, also without punitive measure, the agreement is unbinding. Due to these two points, it is instability that government and enterprise cooperate with each other on storing emergency goods. In order to establish a stable cooperation, there need some punitive measures to restrict the betrayal of each other, and an acceptable cost sharing as well.

\subsection{Stable Cooperative Gaming Model}

Under rational conditions both of them wish to cooperate with each other to reduce their cost. Thus a binding cooperative agreement which has cost sharing and penalties must establish to ensure the stability of cooperation.

Suppose that Extra Payment that government pays to enterprise on cost sharing is $\theta \& \max \left(0, \mathrm{C}_{2}\right) \leq \theta \leq \mathrm{C}_{1}$. When $C_{2}<0$, government may share cost or not share in light of their situation, that is $0 \leq \theta \leq C_{1}$; when $\mathrm{C}_{2} \geq 0$, government must share cost to assure enterprise cooperate with them, that is $\mathrm{C}_{2} \leq \theta \leq \mathrm{C}_{1}$; As a result, $\max \left(0, \mathrm{C}_{2}\right) \leq \theta \leq \mathrm{C}_{1}$.

If one participant offer no co-operation, they will get punishment $\alpha$ to ensure $\mathrm{C}_{2}-\alpha<0$ and $C-\alpha<0$, then $\alpha>\max \left(c_{2}, C\right)>0$, that means betrayal punishment $\alpha$ shall not be less than another's loss caused from betrayal. A now pay function so produced as shown in Table 2 below:

If government betrays, $\mathrm{c}_{2}-\alpha<0$, enterprise accept cooperation, and government will get punishment $\alpha$ to make up for the lost storing cost of enterprise. with enterprise's cooperation, government's paying cost $\mathrm{C}_{1}+\alpha$ must be more than cooperating cost $\theta$ if they still betray, owing to $0 \leq \theta \leq \mathrm{C}_{1}<\mathrm{C}_{1}+\alpha$, cooperation is the optimal strategy of government. And with government's cooperation, enterprise will pay the punishment cost $\alpha$, which is more than the cost of cooperation $\mathrm{C}_{2}-\theta$, owing to $\mathrm{C}_{2}-\theta<0<\mathrm{C}_{2}<\alpha$, enterprise must choose cooperation. As a result, (cooperation, cooperation) is Nash equilibrium.

Same as before, if enterprise choose betrayal, $\mathrm{C}-\alpha<0<\mathrm{C}_{1}$, and government choose cooperation at the same time, who will get the punishment a of enterprise to make up for their lost. if both of them cooperate each other (discussed at (1)), (cooperation, cooperation) is the only Nash equilibrium and is stability.

On Storing Emergency Supplies, establishing cost sharing and penalties will make the cooperation binding and stability between government and enterprise. In the cooperation, government will reduce $\operatorname{cost} \mathrm{C}_{1}-\theta$ $\left(\mathrm{C}_{1}-\theta>0\right)$, and enterprise will get profit $\theta-\mathrm{C}_{2}\left(\theta-\mathrm{C}_{2}>0\right)$. It is a win-win for both of them.

\section{Case Analysis}

Taking earthquakes of Beijing as an example, earthquake emergency supplies can be divided into five categories: Life rescue tools, life-saving class of materials [3], life support class materials, class materials and other postdisaster reconstruction work class supplies. Taking the $550 \mathrm{ml}$ mineral water as emergency supplies example.

Table 2. New pay function.

\begin{tabular}{cccc}
\hline & & \multicolumn{2}{c}{ Enterprise } \\
\cline { 3 - 4 } & & Betray & Cooperate \\
\hline \multirow{2}{*}{ Government } & Betray & $\left(\mathrm{C}_{1}, 0\right)$ & $\left(C_{1}+\alpha, C_{2}+\alpha\right)$ \\
& Cooperate & $(\mathrm{C}-\alpha, \alpha)$ & $\left(\theta, C_{2}-\theta\right)$ \\
\hline
\end{tabular}




\section{Parameters set}

According to market research results to see the average price of $550 \mathrm{ml}$ mineral water is ¥1.5. Retailers Cost is ¥1.1. Taking into account the government’s bulk purchasing, Government purchase price is ¥1.1. At this point the retailer's profit margin

$$
\begin{aligned}
& \text { Profit margin }=\frac{1.5-1.1}{1.5} \times 100 \% \approx 27 \%, \text { Wholesalers' profits are calculated at } 27 \% . \\
& \text { Profit margin }=\frac{1.1-u}{1.1} \times 100 \% \approx 27 \% .
\end{aligned}
$$

cost price of every mineral water is about $¥ 0.8, \mathrm{u}=0.8$. The bottle can be recycled, the market price is about $¥ 0.1$, u0 $=0.1$. Shelf life is 1 year, $t=1$. Mineral storage does not require technical expertise, so enterprise storage costs is the same as government storage costs. $C_{1}=C_{2}$. Average rental price of warehouse in Beijing is about $¥ 0.5$ every square meter every day. Per square meter can store about 5000 bottles of mineral water. So the warehousing costs are:

$$
C_{1}=C_{2}=\frac{0.5 \times 365}{5000} \approx 0.04
$$

The earthquakes that fewer than five ranges do not belong to the strong shock earthquake. It will not cause a lot of damage, so only consider earthquakes above 5. Beijing earthquakes above 5 are 13 times from AD 294 to 2013. Earthquake occurrence probability of Beijing is

$$
\rho=\frac{13}{2013-294}=0.0076
$$

The unit paying cost that government pays when storing that goods per unit time is: (UCT means a unit's paying cost per unit time)

$$
\begin{aligned}
\mathrm{C}_{1} & =\rho . \text { OccuredUCT }+(1-\rho) \cdot \text { Not OccurredUCT } \\
& =\rho \cdot C_{1}+(1-\rho) \cdot\left[c_{1}+\left(\mathrm{p}_{0}-\mathrm{u}_{0}\right) / t\right] \\
& =0.0076 \times 0.04+(1-0.0076) \times[0.04+(1.1-0.1) \div 1] \\
& \approx 1.032
\end{aligned}
$$

The unit paying cost that government pays when storing that goods per unit time is: (UCT means a unit's paying cost per unit time)

$$
\begin{aligned}
\mathrm{C}_{2} & =\rho . \text { OccuredUCT }+(1-\rho) . \text { Not OccurredUCT } \\
& =\rho \cdot\left[c_{2}-\left(\mathrm{p}_{0}-u\right) / t_{0}\right]+(1-\rho) \cdot c_{2} \\
& =0.0076 \times[0.04-(1.1-0.8) \div 1]+(1-0.0076) \times 0.04 \\
& \approx 0.038
\end{aligned}
$$

The pay of government is more than the pay of enterprises in the storage of mineral water, so the government wants to establish partnerships with enterprises to reduce costs. Table $\mathbf{3}$ show the paying function of every participant in the storage of mineral water.

The government hopes to reduce costs through cooperation, so the government's strategy is cooperation. But the corporate dominant strategy of enterprise is always betrayed. At this time, the government cost of cooperation is greater than the cost of betray, so the government chose not to cooperation. The final strategies (cooperate, cooperate) is Nash equilibrium.

But for the whole, the (betray, betray) cost is 1.032; the (cooperate, betray) cost is C; the (betray, cooperate) cost is $1.032+0.04=1.072$; the (cooperate, cooperate) cost is 0.038 . The minimum cost is (cooperate, cooperate), so the government hopes to establish cooperative relations.

In order to establish a stable partnerships, there need some punitive measures to restrict the betrayal of each other, and an acceptable cost sharing as well. The government pays to enterprise on cost sharing is $\theta \& 0.038 \leq \theta \leq 1.032$.

If one participant offers no co-operation, they will get punishment $\alpha$ to ensure $\mathrm{c}_{2}-\alpha<0$ and $\mathrm{C}-\alpha<0$, then $0<\max (0.04, C)<\alpha$, that means betrayal punishment $\alpha$ shall not be less than another's loss caused from betrayal. A now pay function so produced as shown in Table 4 below: 
Table 3. Paying function of mineral water.

\begin{tabular}{cccc}
\hline & & \multicolumn{2}{c}{ Enterprise } \\
\cline { 3 - 4 } & & Betray & Cooperate \\
\hline \multirow{2}{*}{ Government } & Betray & $(1.032,0)$ & $(1.032,0.04)$ \\
& Cooperate & $(C, 0)$ & $(0,0.038)$ \\
\hline
\end{tabular}

Table 4. New pay function of mineral water.

\begin{tabular}{cccc}
\hline & & \multicolumn{2}{c}{ Enterprise } \\
\cline { 3 - 4 } & & Betray & Cooperate \\
\hline \multirow{2}{*}{ Government } & Betray & $(1.032,0)$ & $(1.032+\alpha, 0.04-\alpha)$ \\
& Cooperate & $(\mathrm{C}-\alpha, \alpha)$ & $(\theta, 0.038-\theta)$ \\
\hline
\end{tabular}

(1) If government betrays, $0.04-\alpha<0$, enterprise accept cooperation, and government will get punishment $\alpha$ to make up for the lost storing cost of enterprise. With enterprise's cooperation, government's paying cost $1.032+\alpha$ must be more than cooperating cost $\theta$, owing to $0 \leq \theta \leq 1.032<1.032+\alpha$, cooperation is the optimal strategy of government. And with government's cooperation, enterprise will pay the punishment cost $\alpha$, which is more than the cost of cooperation $0.038-\theta$, owing to $0.038-\theta<0<0.038<\alpha$, enterprise must choose cooperation. As a result, (cooperation, cooperation) is Nash equilibrium.

Same as before, if enterprises choose betrayal $C-\alpha<0<1.032$ and government choose cooperation at the same time, who will get the punishment a lot of enterprise to make up for their lost. If both of them cooperate each other (discussed at (1)), (cooperation, cooperation) is the only Nash equilibrium and is stability.

Finally have a lower overall storage cost 0.038 . The cost savings of per bottle of mineral water is $1.032-$ $0.038=0.994$ per year. In the cooperation, government will reduce cost $1.032-\theta(1.032-\theta>0)$, and enterprise will get profit $\theta-0.038(\theta-0.038>0)$, it is a win-win for both of them.

\section{Acknowledgements}

This work was supported by funding project for Research on emergency material reserve under the integration of Beijing-Tianjin-Hebei. University Under the grant number (15JGB071), and the project for Research on emergency material reserve under the integration of Beijing, Tianjin and Hebei (GJB20161004), the grants from High level scientific research project of Beijing Wuzi University.

\section{References}

[1] Shi, X.Q. (2012) Cooperative Game Theory Cited. Peking University Press, 8.

[2] Fudenberg, D. and Tirole, J. (2010) Game Theory. Renmin University Press, 10.

[3] Ren, Z.Q. (1996) Beijing Seismic History of the Region. National Earthquake News, Section 9, 34-35. 


\section{Submit or recommend next manuscript to SCIRP and we will provide best service for you:}

Accepting pre-submission inquiries through Email, Facebook, LinkedIn, Twitter, etc.

A wide selection of journals (inclusive of 9 subjects, more than 200 journals)

Providing 24-hour high-quality service

User-friendly online submission system

Fair and swift peer-review system

Efficient typesetting and proofreading procedure

Display of the result of downloads and visits, as well as the number of cited articles

Maximum dissemination of your research work

Submit your manuscript at: http://papersubmission.scirp.org/ 